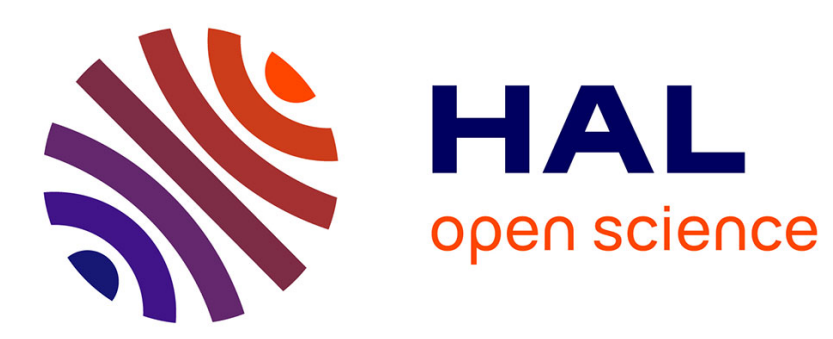

\title{
R\&D cooperation, proximity and distribution of public funding between public and private research sectors
}

\author{
Marie-Laure Cabon-Dhersin, Romain Gibert
}

\section{To cite this version:}

Marie-Laure Cabon-Dhersin, Romain Gibert. R\&D cooperation, proximity and distribution of public funding between public and private research sectors. Manchester School, 2020, 10.1111/manc.12340 . hal-02006489

\section{HAL Id: hal-02006489 \\ https://hal.science/hal-02006489}

Submitted on 4 Feb 2019

HAL is a multi-disciplinary open access archive for the deposit and dissemination of scientific research documents, whether they are published or not. The documents may come from teaching and research institutions in France or abroad, or from public or private research centers.
L'archive ouverte pluridisciplinaire HAL, est destinée au dépôt et à la diffusion de documents scientifiques de niveau recherche, publiés ou non, émanant des établissements d'enseignement et de recherche français ou étrangers, des laboratoires publics ou privés. 


\title{
R\&D cooperation, proximity and distribution of public funding between public and private research sectors
}

\author{
Marie-Laure Cabon-Dhersin, Romain Gibert ${ }^{\dagger}$
}

January 15, 2019

\begin{abstract}
In this paper, we compare the distributions of socially optimal public funding between private and public research sectors in cooperative and non-cooperative R\&D settings in the presence of externalities. We show that the proportion of public funding allocated to the private sector research always increases with the level of inter-firm spillovers but decreases with the concentration of the industry. This share is smaller (larger) when firms cooperate in R\&D than when they do not for high (low) spillovers. Moreover, increases in public knowledge externalities to the private sector due to a closer proximity between the two research sectors increase the share allocated to the public sector regardless of whether firms cooperate or not in R\&D.
\end{abstract}

Key words: Oligopoly, R\&D Cooperation, Spillovers, Knowledge public externalities, public and private research, proximity, Public policy

Code JEL: 031, 038, H4, L5, J48.

\section{Introduction}

Most OECD countries have chosen to support innovation by funding both private and public research activities. These policies aim to stimulate research and increase the stock of knowledge to boost competitiveness and economic growth. The existence of technological spillovers leads firms to underinvest in R\&D because of poor returns. Public funding for private research can reduce the gap between the social and private returns of $R \& D$ by increasing private research investments. Subsidizing $R \& D$ investment has been a

\footnotetext{
${ }^{*}$ Corresponding author: University of Rouen, CREAM, 3 avenue Pasteur, 76100 Rouen, France. (marie-laure.cabon-dhersin@univ-rouen.fr)

${ }^{\dagger}$ University of Rouen, CREAM, 3 avenue Pasteur, 76100 Rouen, France. (romain.gibert1@univrouen.fr)
} 


\begin{tabular}{l|c|c|c|c|} 
& \multicolumn{2}{|c|}{$\begin{array}{c}\text { Proportion of public R\&D funding } \\
\text { allocated to private (public) bodies }\end{array}$} & \multicolumn{2}{c|}{$\begin{array}{c}\text { Proportion of direct } \\
\text { (indirect) }\end{array}$} \\
& $\mathbf{2 0 0 5}$ & $\mathbf{2 0 1 0}$ & $\mathbf{2 0 0 5}$ & $\mathbf{2 0 1 0}$ \\
\hline Germany & $10.89 \%(89.11 \%)$ & $10.14 \%(89.86 \%)$ & $100 \%$ & $100 \%$ \\
\hline Japan & $16.85 \%$ & $10.23 \%$ & $20.58 \%$ & $35.42 \%$ \\
\hline Sweden & $13.19 \%$ & $14.79 \%$ & $100 \%$ & $100 \%$ \\
\hline Netherlands & $12.84 \%$ & $17.44 \%$ & $33.02 \%$ & $21.16 \%$ \\
\hline Spain & $21.27 \%$ & $23.35 \%$ & $68.22 \%$ & $79.29 \%$ \\
\hline Canada & $23.03 \%$ & $23.60 \%$ & $13.18 \%$ & $12.24 \%$ \\
\hline South-Korea & $31.78 \%$ & $31.07 \%$ & $45.16 \%$ & $50.81 \%$ \\
\hline France & $19.86 \%$ & $33.75 \%$ & $76.46 \%$ & $34.27 \%$ \\
\hline USA & $25.22 \%$ & $33.47 \%$ & $81.09 \%$ & $83.85 \%$ \\
\hline
\end{tabular}

Table 1: Distribution of public R\&D funding between the public and private sectors.

Source: OECD.Stat 2012

widespread policy in many countries over the past thirty to fifty years. Governments can also act on public research to increase its economic benefit to the private sector. Many empirical studies have shown that research conducted in public laboratories or universities benefits private research (Jaffe, 1989; Audretsch et al., 2002; Cohen et al., 2002; AutantBernard, 2001; Cohen et al., 1994; Veugelers and Cassiman, 2005). Other studies in the geography of innovation have added an important spatial dimension to the discussion by showing that the positive effects are greater the closer the private and public research groups are (Anselin et al., 1997; Cooke, 2001; Furman et al., 2006; Autant-Bernard and LeSage, 2011).

Governments share out public R\&D funding differently between the two research sectors but all countries allocate a greater portion (65-90\%) to the public sector. Table 1 shows how public funding is divided between private companies on the one hand, and universities and public research institutes (PRIs) on the other. ${ }^{1}$ This distribution seems to have varied little between 2005 and 2010, except in France and the USA, where the private sector's share has increased. Public support for private research can be either direct (grants, loans or procurements) or indirect ( $R \& D$ tax incentives, tax credits or allowances). In this article, we do not differentiate between funding measures but investigate how the distribution of public research funds between the two sectors affects social welfare.

Alongside these funding policies, governments encourage cooperation between research groups. The benefits of cooperation in R\&D are well established (see Marinucci (2012)).

\footnotetext{
${ }^{1}$ The share of public R\&D subsidies allocated to the public sector is defined as the cost of all government-funded R\&D in the higher education sector plus all intramural government expenditures on $\mathrm{R} \& \mathrm{D}$ funded by the government itself or by the higher education sector. The share of public $\mathrm{R} \& \mathrm{D}$ funding allocated to the private sector is defined as the sum of firms' government-funded expenditure on $R \& D$ plus the estimated cost of $R \& D$ tax incentives, if any.
} 
The first theoretical analyses proposed by Katz (1986); d'Aspremont and Jacquemin (1988); Kamien et al. (1992), and the subsequent generalizations and extensions (Amir, 2000; Amir and Wooders, 2000; Amir et al., 2003; Cabon-Dhersin, 2008; Cabral, 2000; De Fraja and Silipo, 2002; Lambertini et al., 2003; Motta, 1992; Poyago-Theotoky, 1995; Salant and Shaffer, 1998), ${ }^{2}$ show how cooperation through R\&D coordination and/or information sharing between firms stimulates $R \& D$ and can thus improve social welfare. The anticipated benefits of $R \& D$ cooperation have lead governments to set cooperation as a condition for funding firms but also public bodies (in the EU's Horizon2020 programme for instance). The research cluster policies adopted in all OECD countries have the same rationale. While there have been many empirical studies evaluating these policies, their efficiency in the presence of public research bodies has seldom been studied on a theoretical basis. Among the few contributions on this topic, Cassiman's (2000) shows that when policymakers add a lump-sum subsidy to RJV-forming allowances, they can differentiate welfare-improving RJVs from the ones formed for anti-competitive purposes. Hinloopen's (1997, 2000, 2001) show that when providing optimal R\&D subsidies to firms, it makes no difference whether they cooperate or not. The outcome is more nuanced if public subsidies are allocated to public research bodies to promote in turn the R\&D investments of cooperating firms (Cabon-Dhersin and Gibert, 2018).

We would like to revisit this question of public support in the context of R\&D cooperation in the private sector in the presence of active public research bodies. Our analysis focuses on the $n$ firms case of the seminal R\&D investment model first introduced by d'Aspremont and Jacquemin (1988). We consider a three-stage game that involves a government and public and private research sectors that do not compete on innovation. We assume that the public research body does not generate a profit and can be seen as a means of supporting private innovation through the knowledge externalities it produces. We also assume that firms do not appropriate all their R\&D output, i.e. that there are spillovers. In the first stage, the government chooses the optimal policy to subsidize private $R \& D$ investments. In the second stage, firms decide how much to spend on $R \& D$ and the public research sector, which is fully supported by state funding, chooses how much to invest in (public) research. Two scenarios are considered for the second stage: in the first, firms conduct their research non-cooperatively; in the second, their research activities are cooperative. In the final stage, firms decide how much to sell in an oligopolistic market. Our question then is whether R\&D cooperation between firms and their proximity to the public research sector alters the distribution of financial aid between the two sectors.

This theoretical study yields several interesting results. We show for instance that a research funding policy that optimally stimulates both public and private research investments leads to better performance (in terms of consumer surplus and social welfare) than a policy that optimally subsidizes just private or just public research. The higher public knowledge externalities to the private research sector that arise when the two research sectors are closer improve the effectiveness of the research funding policy in terms of overall surplus regardless of whether firms cooperate or not in $\mathrm{R} \& \mathrm{D}$. This greater proximity,

\footnotetext{
${ }^{2}$ And many more, the list is not exhaustive.
} 
geographically and/or through partnerships, implies that a larger share of public R\&D funding go to the public sector. Similarly, when inter-firm spillovers are high (weak protection of intellectual property rights), firms receive a smaller share of public funding in the cooperative scenario than in the non-cooperative one, the socially optimal proportion of the private sector's research spending subsidized by the state being lower. Conversely, when spillovers are low, social welfare is optimized when cooperating firms receive a larger share of public funding. Our results also suggest that while in the presence of state-funded public research bodies, it makes no difference whether firms cooperate or not, the outcomes are always better with public support for private R\&D than without. Nevertheless, if inter-firm spillovers are high, funding cooperating (rather than non-cooperating) firms is preferential because of the lower associated social cost.

We first present the model and then derive equilibrium results for both scenarios (cooperation and non-cooperation in $\mathrm{R} \& \mathrm{D}$ ). In the third section, we compare and discuss the outcomes of both scenarios before concluding.

\section{The model}

We will consider a private research sector, $p r$, consisting of $n$ identical competing firms $i=1, \ldots, n$ that produce a single homogeneous good. The demand function is simply:

$$
P(Q)=a-Q
$$

where the level of production is $Q=\sum_{i=1}^{n} q_{i}$, with $Q \leq a$ and $i \neq j, i, j \in\{1, \ldots, n\}$.

Following d'Aspremont and Jacquemin (1988), the firms invest upstream in R\&D either non-cooperatively or cooperatively (respectively the $n c$ and $c$ scenarios) to lower their production costs. The marginal cost of production is constant and equal to $c$. The firms do not appropriate all the $R \& D$ they produce. Thus a proportion $\beta \in(0,1]$ of firm $i$ 's R\&D investments benefits firm $j$ at no cost to the latter. $\beta$ is given exogenously and is not affected by the firms' $R \& D$ behavior. When $\beta=0$, each firm appropriates all its $\mathrm{R} \& \mathrm{D}$ whereas $\beta=1$ corresponds to a situation in which the firms share all their $\mathrm{R} \& \mathrm{D}$ results. Inter-firm spillovers reduce a firm's production costs but also discourage new R\&D investments because these would help the competition decrease its costs. Concurrently, the private sector $(p r)$ benefits as a whole from a fraction $\alpha(\alpha \in(0,1])$ of the $R \& D$ carried out in the public sector $(p u)$. This exogenous parameter $(\alpha)$ corresponds to public knowledge externalities. ${ }^{3}$ It depends on a variety of factors such as the type of knowledge produced by the public sector (generic vs. applied) and firms' ability to use and integrate

\footnotetext{
${ }^{3}$ We assume here that the public sector does not benefit from spillovers produced by the private sector. The existence of asymmetric externalities is consistent with the empirical literature (Jaffe, 1989; Audretsch et al., 2002; Cohen et al., 2002; Autant-Bernard, 2001; Cohen et al., 1994; Veugelers and Cassiman, 2005): spillovers from universities have been identified as a key source of corporate innovation but the public research sector does not benefit from knowledge spillover. It follows from setting $\alpha=0$ that only the private sector invests in $R \& D$ activity.
} 
it, the physical proximity of the two sectors, and the efficiency of research networks. Empirical studies show that physical proximity promotes exchanges between the two sectors (increases $\alpha$ ). Since public research is a public good, one can assume that it is completely appropriated $(\alpha=1)$ when private and public researchers work in the same place.

Firm $i$ 's effective level of R\&D, $X_{i}$ is therefore the sum of its R\&D-output level, $x_{i}$, a proportion $\beta$ of the remaining firms' $\mathrm{R} \& \mathrm{D}, \beta \sum_{j \neq i} x_{j}$, and a proportion of the public sector's research output, $\alpha x_{p u}$,

$$
X_{i}=x_{i}+\beta \sum_{j \neq i} x_{j}+\alpha x_{p u}, \quad i=1, \ldots, n
$$

The firms' production cost function is thus:

$C_{i}=\left(c-X_{i}\right) q_{i}=\left(c-x_{i}-\beta \sum_{j \neq i} x_{j}-\alpha x_{p u}\right) q_{i}, \quad a>c>x_{i}+\beta \sum_{j \neq i} x_{j}+\alpha x_{p u}>0, \quad i=1, \ldots, n$

Furthermore, R\&D activities in the two sectors lead to quadratic costs (with diminishing returns): $\gamma x^{2}{ }^{4}$ In the literature, $\gamma$ is usual interpreted as a measure of R\&D efficiency and $\frac{1}{\gamma}$ can be interpreted as the cost effectiveness of $R \& D$, with higher values being favorable of course. We assume that this can vary between research sectors, with $\gamma_{p u}$ for the public sector and $\gamma_{p r}$ for the private sector. Firms thus have to spend $\gamma_{p r} x_{i}^{2}$ to reduce their production costs by $x_{i}$, whereas the public research sector spends $\gamma_{p u} x_{p u}^{2}$ to reduce the firms' production costs by $\alpha x_{p u}$.

The presence of spillovers, $\beta \in(0,1]$, justifies government financial aid to both research sectors. The state thus covers all of the public sector's research spending and a proportion $s \in(0,1]$ of the private sector's. Some amount of subsidy is given for every dollar spent on R\&D.

Consequently, firm $i$ receives a government subsidy $s \gamma_{p r} x_{i}^{2}$ and the public sector receives $\gamma_{p u} x_{p u}^{2}$.

The firms' profit function is then:

$$
\pi_{i}=(a-Q) q_{i}-\left(c-x_{i}-\beta \sum_{j \neq i} x_{j}-\alpha x_{p u}\right) q_{i}-(1-s) \gamma_{p r} x_{i}^{2}
$$

${ }^{4}$ This is the usual assumption for R\&D costs, which we choose to follow in a first analysis. The R\&D models proposed by d'Aspremont and Jacquemin (1988) (AJ) and Kamien et al. (1992) (KMZ) have been compared several times. In contrast with the KMZ model, AJ's does not consider diminishing returns for research when calculating spillovers, which are outside the research process. This tends to make the $\mathrm{R} \& \mathrm{D}$ process in the AJ model more productive and to increase the level of the equilibrium results. One can switch between the two models by replacing $\gamma$ with $(1+\beta) \gamma$ (see Amir (2000) pp. 1030-31, Hinloopen (2000)). Changing the R\&D cost structure qualitatively does not affect any of the conclusions presented here. 
We treat the government as an active player able to adjust the relevant policies. The government chooses the policy mix $\left(s^{n c, c}, x_{p u}^{n c, c}\right)$ that maximize its social welfare function. This welfare function is defined as the sum of consumer and producer surplus minus the cost of government support for R\&D (noted by $S C$ ):

$$
S W=\underbrace{\frac{Q^{2}}{2}}_{\text {Consumer surplus }}+\underbrace{\sum_{i=1}^{n} \pi_{i}}_{\text {Producer surplus }}-\underbrace{\left.\left(s \gamma_{p r} \sum_{i=1}^{n} x_{i}^{2}+\gamma_{p u} x_{p u}^{2}\right)\right)}_{\text {Social cost of the R\&D funding=SC }}
$$

which after aggregating yields

$$
S W=\frac{Q^{2}}{2}+\sum_{i=1}^{n}\left((a-Q) q_{i}-C_{i}-\gamma_{p r} x_{i}^{2}\right)-\gamma_{p u} x_{p u}^{2}
$$

The public subsidy allocated to the private sector disappears from the welfare function. This means that the subsidy, $s$, has no direct effect on welfare or on the public research sector's objective function. Nevertheless, the subsidies still have an indirect effect on the public sector's R\&D output, though the firms' R\&D choices.

Ultimately, the private sector's share of public funding is given by: ${ }^{5}$

$$
\theta=\frac{s \gamma_{p r} \sum_{i=1}^{n} x_{i}^{2}}{s \gamma_{p r} \sum_{i=1}^{n} x_{i}^{2}+\gamma_{p u} x_{p u}^{2}} \in(0,1)
$$

We will investigate how socially optimal public funding is distributed between the two research sectors when firms cooperate in $R \& D$ and when they do not:

- In the first scenario $(n c)$, the firms do not cooperate in R\&D: they compete both during the $R \& D$ stage and during the production stage.

- In the second scenario $(c)$, the firms coordinate their $R \& D$ investments to maximize the sum of their profits but still engage in Cournot competition in the production stage. ${ }^{6}$

The structure of the game is as follows: in the first stage, the government chooses the welfare-optimal level of R\&D subsidy, s. In the second, the firms choose the $R \& D$

\footnotetext{
${ }^{5}$ If all government financial support for $\mathrm{R} \& \mathrm{D}$ is allocated to the private sector $\left(\right.$ meaning $x_{p u}=0$ and $s>0), \theta=1$. In contrast, when the government chooses to only cover the public sector's research spending (meaning $x_{p u}>0$ and $s=0$ ), $\theta=0$. Our analysis focuses on funding policies that support both research sectors.

${ }^{6}$ This approach, referred to as an $\mathrm{R} \& \mathrm{D}$ cartel, is typical in the literature on $\mathrm{R} \& \mathrm{D}$ cooperation. Our analysis also covers the case in which $\beta=1$, that is, the firms form an RJV cartel whereby they coordinate their R\&D levels and share all their knowledge.
} 
output that maximizes their profits, whereas the public sector chooses the level of R\&D that maximizes social welfare. ${ }^{7}$ In the last stage, firms play a standard Cournot game. We assume that the firms, the government and the public research sector know how their actions will affect those of all the other actors in the next stages of the game, which requires subgame perfection. We can now study the Subgame Perfect Nash Equilibrium (SPNE henceforth) for the $n c$ and $c$ scenarios.

\section{The non-cooperative scenario}

In this scenario, firms compete in both the production and the R\&D stage. In the third stage, each firm chooses the output that maximizes its operating profits. The equilibrium output of firm $i$ is given by:

$$
q_{i}\left(x_{i}, x_{j}, x_{p u}\right)=\frac{A+(n-\beta(n-1)) x_{i}+(2 \beta-1)(n-1) x_{j}+\alpha x_{p u}}{n+1}
$$

with $i=1, \ldots, n$.

where $A=a-c$ is the size of the market.

Firm $i$ 's profit is then:

$$
\pi_{i}\left(x_{i}, x_{j}, x_{p u}\right)=\left(\frac{A+(n-\beta(n-1)) x_{i}+(2 \beta-1)(n-1) x_{j}+\alpha x_{p u}}{n+1}\right)^{2}-(1-s) \gamma_{p r} x_{i}^{2}
$$

\subsection{R\&D stage in the non-cooperative scenario}

In the second stage, the public research sector chooses the $R \& D$ spending that maximizes social welfare (Equation 3) whereas the private firms choose the R\&D investment that maximizes their profits (Equation 6$)$. Given $q_{i}\left(x_{i}, x_{j}, x_{p u}\right)$ from above, the relevant firstorder conditions rise to the following R\&D best-response function. ${ }^{8}$

$$
x_{p r}\left(x_{p u}\right)=\frac{(n-\beta(n-1))\left(A+\alpha x_{p u}\right)}{\gamma_{p r}(1-s)(n+1)^{2}-(n-\beta(n-1))(1+\beta(n-1))}
$$

with $x_{i}=x_{j}=x_{p r}$

Equations 3 et 5 can be used to express social welfare in terms of $x_{p r}$ and $x_{p u}$ :

$$
S W\left(x_{p r}, x_{p u}\right)=\frac{Q^{2}}{2}-n\left(q^{2}-\gamma_{p r} x_{p r}^{2}\right)-\gamma_{p u} x_{p u}^{2}
$$

\footnotetext{
${ }^{7}$ This set-up is similar to some of the models used in the mixed markets literature (Gil-Molto et al., 2011; Gil-Moltó et al., 2018; Kesavayuth and Zikos, 2013).

${ }^{8}$ The second-order condition is that $\gamma_{p r}(1-s)(n+1)^{2}>(n-\beta(n-1))(1+\beta(n-1))$
} 


$$
=\frac{n(n+2)}{2}\left(\frac{A+(1+\beta(n-1)) x_{p r}+\alpha x_{p u}}{n+1}\right)^{2}-n \gamma_{p r} x_{p r}^{2}-\gamma_{p u} x_{p u}^{2}
$$

The optimal public investment optimizes the welfare function: ${ }^{9}$

$$
\frac{\partial S W}{\partial x_{p u}}=n(n+2) \frac{\partial q}{\partial x_{p u}} q-2 \gamma_{p u} x_{p u}=0
$$

$\underbrace{\frac{n(n+2) \alpha}{(n+1)^{2}}\left(A+(1+\beta(n-1)) x_{p r}+\alpha x_{p u}\right)}_{\text {Marginal social return of the public research investment }}=\underbrace{2 \gamma_{p u} x_{p u}}_{\text {Marginal social cost of the public research investment }}$

so that the public sector's best response is

$$
x_{p u}\left(x_{p r}\right)=\frac{n(n+2) \alpha\left(A+(1+\beta(n-1)) x_{p r}\right)}{2 \gamma_{p u}(n+1)^{2}-n(n+2) \alpha^{2}}
$$

Clearly, public and private research investments are strategic complements. Public research boosts private research by reducing the latter's production costs, stimulating production. In addition, increases in private sector $R \& D$ lead the public sector to increase research investment to maximise social welfare. The optimal level of research investment in the public sector is the value that equates the marginal social return of the investment to its marginal social cost (see Equation 8).

Equations (7) and (9) can be rewritten to obtain the R\&D-output levels in the second stage:

$$
\begin{aligned}
& x_{p r}(s)=\frac{2(n-\beta(n-1))}{\frac{\gamma_{p r}}{\gamma_{p u}}\left(2 \gamma_{p u}(n+1)^{2}-n(n+2) \alpha^{2}\right)(1-s)-2(n-\beta(n-1))(1+\beta(n-1))} A \\
& x_{p u}(s)=\frac{\frac{\gamma_{p r}}{\gamma_{p u}} n(n+2) \alpha(1-s)}{\frac{\gamma_{p r}}{\gamma_{p u}}\left(2 \gamma_{p u}(n+1)^{2}-n(n+2) \alpha^{2}\right)(1-s)-2(n-\beta(n-1))(1+\beta(n-1))} A
\end{aligned}
$$

Here, when the local stability condition is verified, the denominator is positive. ${ }^{10}$

Thus public externalities $(\alpha)$ promote R\&D levels in both sectors. Recent studies (Becker, 2015; Dimos and Pugh, 2016) have found no evidence of a crowding-out effect: subsidies, $s$, increase both private and public R\&D output because the level of subsidy appears negatively in the denominator (Equations 10 and 11).

\footnotetext{
${ }^{9}$ The second-order condition is that $2(n+1)^{2} \gamma_{p u}>n(n+2) \alpha^{2}$.

${ }^{10}$ For a discussion of stability in oligopolies see Leahy and Neary (1997).
} 
Substituting these expressions for $x_{p r}(s)$ and $x_{p u}(s)$ into Equation 5 gives:

$$
q(s)=\frac{2 \gamma_{p r}(n+1)(1-s)}{\frac{\gamma_{p r}}{\gamma_{p u}}\left(2 \gamma_{p u}(n+1)^{2}-n(n+2) \alpha^{2}\right)(1-s)-2(n-\beta(n-1))(1+\beta(n-1))} A
$$

At the end of the second stage, the firms' profits and social welfare depend on the subsidy $s$ as follows:

$$
\begin{aligned}
\pi(s)= & q(s)^{2}-(1-s) \gamma_{p r} x_{p r}^{2}(s) \\
& =\frac{4 \gamma_{p r}(1-s)\left((n+1)^{2} \gamma_{p r}(1-s)-(n-\beta(n-1))^{2}\right)}{\left(\frac{\gamma_{p r}}{\gamma_{p u}}\left(2 \gamma_{p u}(n+1)^{2}-n(n+2) \alpha^{2}\right)(1-s)-2(n-\beta(n-1))(1+\beta(n-1))\right)^{2}} A^{2}
\end{aligned}
$$

and

$$
\begin{aligned}
S W(s)= & \frac{n(n+2)}{2} q(s)^{2}-n \gamma_{p r} x_{p r}^{2}(s)-\gamma_{p u} x_{p u}^{2}(s) \\
= & \frac{n \gamma_{p r}\left((n+2) \frac{\gamma_{p r}}{\gamma_{p u}}\left(2(n+1)^{2} \gamma_{p u}-n(n+2) \alpha^{2}\right)(1-s)^{2}-4(n-\beta(n-1))^{2}\right)}{\left(\frac{\gamma_{p r}}{\gamma_{p u}}\left(2 \gamma_{p u}(n+1)^{2}-n(n+2) \alpha^{2}\right)(1-s)-2(n-\beta(n-1))(1+\beta(n-1))\right)^{2}} A^{2}
\end{aligned}
$$

\subsection{Optimal R\&D subsidy in the non-cooperative scenario}

The government chooses the R\&D subsidy that maximizes welfare. Substituting the equilibrium R\&D-output level (Equations 10 and 11) and quantities (Equation 12) into the social welfare objective function and solving the FOC with respect to $s,{ }^{11}$ yields the optimal R\&D subsidy:

$$
\begin{gathered}
\frac{\partial S W}{\partial s}=n(n+2) \frac{\partial q(s)}{\partial s} q(s)-2 n \gamma_{p r} \frac{\partial x_{p r}(s)}{\partial s} x^{p r}(s)-2 \gamma_{p u} \frac{\partial x_{p u}(s)}{\partial s} x_{p u}(s)=0 \\
\Leftrightarrow s^{* n c}=\frac{\beta(n-1)(4+n)+(2-n)}{(2+n)(1+\beta(n-1))}
\end{gathered}
$$

which is positive only iff $\beta>\bar{\beta}=\frac{n-2}{(n-1)(4+n)}$.

As shown by Inci (2009), subsidizing R\&D investments is desirable only when the technological spillover exceeds a threshold that is dependent on the number of firms in

\footnotetext{
${ }^{11}$ The second-order condition is always verified.
} 
the industry. ${ }^{12}$ In a competitive environment, firms have a stronger incentive to invest in $\mathrm{R} \& \mathrm{D}$ to gain a competitive advantage over their rivals. But above a certain spillover level, this "competitive" effect is outbalanced by the "spillover" effect, which discourages R\&D investments (see Leahy and Neary (1997)).

Beyond the threshold $\bar{\beta}$ and given the number of firms, $n \geq 2$, in the private sector, the optimal value $s^{* n c}$ is increasing in inter-firms spillovers:

$$
\frac{\partial s^{* n c}}{\partial \beta}=\frac{2(n-1)(n+1)}{(2+n)(1+\beta(n-1))^{2}}>0
$$

The more information leakage there is, the more beneficial it is to support R\&D investments by increasing R\&D funding for firms.

Substituting the expression for the optimal subsidy (Equation 15) into the preceding equations (Equations from 10 to 14 ) yields the equilibrium non-cooperative results presented in Table 2 (obtained only for $s_{n c}>0$, i.e. $\beta \geq \bar{\beta}$ ).

The private (public) sector's share of public R\&D funding can be deduced from Equation 4:

$$
\left\{\begin{array}{l}
\theta^{n c}=\frac{(\beta(n-1)(4+n)+(2-n))(1+\beta(n-1))}{(\beta(n-1)(4+n)+(2-n))(1+\beta(n-1))+n(n+2) \alpha^{2} \frac{\gamma p r}{\gamma p u}} \\
\left(1-\theta^{n c}\right)=\frac{n(n+2) \alpha^{2} \frac{\gamma p r}{\gamma p u}}{(\beta(n-1)(4+n)+(2-n))(1+\beta(n-1))+n(n+2) \alpha^{2} \frac{\gamma p r}{\gamma p u}}
\end{array}\right.
$$

with $\theta^{n c}>0$ positive only iff $\beta>\bar{\beta}=\frac{n-2}{(n-1)(4+n)}$

\section{The cooperative scenario}

In this section we consider the situation in which firms, instead of maximizing their individual profits during the $R \& D$ stage, choose the $R \& D$ activity that maximizes the sum of profits.

\subsection{R\&D stage in the cooperative scenario}

Since the last stage of the game remains non-cooperative, we return to equation 5 . In the R\&D stage, firms maximize their joint profits:

$$
\Pi=\sum_{i=1}^{n}\left(q_{i}^{2}-(1-s) \gamma_{p r} x_{i}^{2}\right)
$$

\footnotetext{
${ }^{12}$ The implication of this result is that $R \& D$ investments should be taxed because there is too much $\mathrm{R} \& \mathrm{D}$ whenever $\beta \leq \bar{\beta}$ (Inci, 2009). Note moreover that the threshold $\bar{\beta}$ increases with the number of firms up to $n=4$, then decreases. This confirms that excessive $\mathrm{R} \& \mathrm{D}$ is more likely when the industry is highly concentrated. The question of $\mathrm{R} \& \mathrm{D}$ taxation, although interesting, is beyond the scope of this work.
} 
The symmetric solution $x_{p r}=x_{i}=x_{j}$ and the FOCs yield the firms' best response when they choose to coordinate their R\&D spending: ${ }^{13}$

$$
x_{p r}=\frac{(1+\beta(n-1))\left(A+\alpha x_{p u}\right)}{(n+1)^{2} \gamma_{p r}(1-s)-(1+\beta(n-1))^{2}}
$$

The public sector's reaction function is the same as in the $n c$ scenario (see Equation 9 ), so that the level of production at the end of the second stage is:

$$
q\left(x_{p r}, x_{p u}\right)=\frac{A+(1+\beta(n-1)) x_{p r}+\alpha x_{p u}}{n+1}
$$

The R\&D outputs as a function of the level of subsidy $s$ are obtained from the best response functions (Equations (9) and (18)):

$$
\begin{aligned}
& x_{p r}(s)=\frac{2(1+\beta(n-1))}{\frac{\gamma_{p r}}{\gamma_{p u}}\left(2(n+1)^{2} \gamma_{p u}-n(n+2) \alpha^{2}\right)(1-s)-2(1+\beta(n-1))^{2}} A \\
& x_{p u}(s)=\frac{\frac{\gamma_{p r}}{\gamma_{p u}} n(n+2) \alpha(1-s)}{\frac{\gamma_{p r}}{\gamma_{p u}}\left(2(n+1)^{2} \gamma_{p u}-n(n+2) \alpha^{2}\right)(1-s)-2(1+\beta(n-1))^{2}} A
\end{aligned}
$$

The amount produced by both firms as a function of $s$ is:

$$
q(s)=\frac{2 \gamma_{p r}(n+1)(1-s)}{\frac{\gamma_{p r}}{\gamma_{p u}}\left(2(n+1)^{2} \gamma_{p u}-n(n+2) \alpha^{2}\right)(1-s)-2(1+\beta(n-1))^{2}} A
$$

The firms' profit as a function of $s$ is therefore:

$$
\pi(s)=\frac{4 \gamma_{p r}(1-s)\left(\gamma_{p r}(n+1)^{2}(1-s)-(1+\beta(n-1))^{2}\right)}{\left(\frac{\gamma_{p r}}{\gamma_{p u}}\left(2(n+1)^{2} \gamma_{p u}-n(n+2) \alpha^{2}\right)(1-s)-2(1+\beta(n-1))^{2}\right)^{2}} A^{2}
$$

\subsection{Optimal R\&D subsidy in the cooperative scenario}

The optimal R\&D subsidy, $s^{c}$, meets the governments aim of maximizing social welfare. Given Equations 20, 21 and 22, the net total surplus in the cooperative scenario can be written

$$
S W(s)=\frac{n \gamma_{p r}\left((n+2) \frac{\gamma_{p r}}{\gamma_{p u}}\left(2(n+1)^{2} \gamma_{p u}-n(n+2) \alpha^{2}\right)(1-s)^{2}-4(1+\beta(n-1))^{2}\right)}{\left(\frac{\gamma_{p r}}{\gamma_{p u}}\left(2(n+1)^{2} \gamma_{p u}-n(n+2) \alpha^{2}\right)(1-s)-2(1+\beta(n-1))^{2}\right)^{2}} A^{2}
$$

\footnotetext{
${ }^{13}$ The second-order condition is $(n+1)^{2} \gamma_{p r}(1-s)>(1+\beta(n-1))^{2}$.
} 
The optimal R\&D subsidy maximizes this expression and is given by ${ }^{14}$

$$
s^{* c}=\frac{n}{n+2}
$$

This means that in a cooperative context, maximizing welfare requires that a proportion $\frac{n}{n+2}$ of firms' R\&D expenditure be subsidized. In contrast with the non-cooperative scenario, the optimal level of R\&D subsidy does not depend on spillovers and increases only with the number of cooperating firms. Comparing these results with those from the non-cooperative scenario, we obtain lemma 1 :

\section{Lemma 1}

$$
s^{* c}<s^{* n c} \quad \text { iff } \quad \beta>0.5, \quad s^{* c}=s^{* n c} \quad \text { iff } \quad \beta=0.5 \quad \text { and } \quad s^{* c}>s^{* n c} \quad \text { iff } \quad \beta<0.5
$$

Proof: The proof is straightforward.

The optimal R\&D subsidy encourages firms to invest substantially in $R \& D$ by reducing their R\&D costs and thus increasing their profits, which is always socially beneficial (see Proposition 1 below). When spillovers are low $(\beta<0.5)$, the $\mathrm{R} \& \mathrm{D}$ output in the cooperative case is lower than the non-cooperative $R \& D$ output in the absence of subsidies. The government thus needs to increase its subsidies $s^{c}$ for cooperative R\&D investments. When spillovers are high in contrast, the optimal subsidy $s^{n c}$ has to be higher for noncooperative $R \& D$ investments to stimulate private $R \& D$.

Substituting the optimal level of R\&D subsidy $s^{c}$ into the preceding equations (Equations 20, 21 and 22) yields the SPNE solutions in the cooperative case. Table 2 summarizes all our results. For a number of firms $n \geq 2$, we can also determine the optimal share of public R\&D support that should be allocated to fund private and public research (respectively $\theta^{c}$ and $1-\theta^{c}$ ):

$$
\left\{\begin{array}{l}
\theta^{c}=\frac{(1+\beta(n-1))^{2}}{(1+\beta(n-1))^{2}+(n+2) \alpha^{2} \frac{\gamma p r}{\gamma_{p u}}} \\
\left(1-\theta^{c}\right)=\frac{(n+2) \alpha^{2} \frac{\gamma p r}{\gamma_{p u}}}{(1+\beta(n-1))^{2}+(n+2) \alpha^{2} \frac{\gamma p r}{\gamma_{p u}}}
\end{array}\right.
$$

with $\theta^{c} \in(0,1) \quad \forall \beta, \alpha \in(0,1]$

\footnotetext{
${ }^{14}$ The second order condition is always verified.
} 


\begin{tabular}{|c|c|}
\hline \multicolumn{2}{|c|}{$x_{p r}^{n c}=x_{p r}^{c}=\frac{(2+n)(1+\beta(n-1))}{\Omega} A$} \\
\hline \multicolumn{2}{|c|}{$x_{p u}^{n c}=x_{p u}^{c}=\frac{n(n+2) \alpha \frac{\gamma p r}{\gamma p u}}{\Omega} A$} \\
\hline$\pi^{n c}=\frac{2 \gamma_{p r}\left(2(n+1)^{2} \gamma_{p r}-(n+2)(n-\beta(n-1))(1+\beta(n-1))\right)}{\Omega^{2}} A^{2}$ & $\pi^{c}=\frac{2 \gamma_{p r}\left(2(n+1)^{2} \gamma_{p r}-(n+2)(1+\beta(n-1))^{2}\right)}{\Omega^{2}} A^{2}$ \\
\hline \multicolumn{2}{|c|}{$Q^{n c}=Q^{c}=\frac{2 n(n+1) \gamma_{p r}}{\Omega} A$} \\
\hline \multicolumn{2}{|c|}{$S W^{n c}=S W^{c}=\frac{n(n+2) \gamma_{p r}}{\Omega} A^{2}$} \\
\hline
\end{tabular}

Table 2: Equilibrium solutions in $n c$ and $c$ scenarios with $\Omega=\frac{\gamma_{p r}}{\gamma_{p u}}\left(2(n+1)^{2} \gamma_{p u}-n(n+2) \alpha^{2}\right)-(2+n)(1+\beta(n-1))^{2}$

\section{Comparisons and results}

We compare the outcomes of the $n c$ and $c$ scenarios in a regulated oligopoly (supported by socially-optimal subsidies) with the unregulated market equilibrium (meaning $s=0$ ).

Proposition $1 \forall \alpha \in(0,1]$,

(i) if $\beta>0.5$,

$$
\left\{\begin{array}{l}
\left.x_{p r}^{c}\right|_{s *^{c}}=\left.x_{p r}^{n c}\right|_{s *^{n c}}>\left.x_{p r}^{c}\right|_{s=0}>\left.x_{p r}^{n c}\right|_{s=0} \\
\left.x_{p u}^{c}\right|_{s *^{c}}=\left.x_{p u}^{n c}\right|_{s^{n c}}>\left.x_{p u}^{c}\right|_{s=0}>\left.x_{p u}^{n c}\right|_{s=0} \\
\left.Q^{c}\right|_{s *^{c}}=\left.Q^{n c}\right|_{s *^{n c}}>\left.Q^{c}\right|_{s=0}>\left.Q^{n c}\right|_{s=0} \\
\left.\pi^{n c}\right|_{s *^{n c}}>\left.\pi^{c}\right|_{s *^{c}} \\
\left.S W^{c}\right|_{s *^{c}}=\left.S W^{n c}\right|_{s *^{n c}}>\left.S W^{c}\right|_{s=0}>\left.S W^{n c}\right|_{s=0}
\end{array}\right.
$$

and $s^{* c}<s^{* n c} \Rightarrow S C^{* c}<S C^{* n c}$

(ii) if $\beta<0.5$,

$$
\begin{aligned}
& \left\{\begin{array}{l}
\left.x_{p r}^{c}\right|_{s^{* c}}=\left.x_{p r}^{n c}\right|_{s^{* n c}}>\left.x_{p r}^{n c}\right|_{s=0}>\left.x_{p r}^{c}\right|_{s=0} \\
\left.x_{p u}^{c}\right|_{s^{* c}}=\left.x_{p u}^{n c}\right|_{s^{* n c}}>\left.x_{p u}^{n c}\right|_{s=0}>\left.x_{p u}^{c}\right|_{s=0} \\
\left.Q^{c}\right|_{s^{* c}}=\left.Q^{n c}\right|_{s^{* n c}}>\left.Q^{n c}\right|_{s=0}>\left.Q^{c}\right|_{s=0} \\
\left.\pi^{c}\right|_{s^{* c}}>\left.\pi^{n c}\right|_{s^{* n c}} \\
\left.S W^{c}\right|_{s^{* c}}=\left.S W^{n c}\right|_{s^{* n c}}>\left.S W^{n c}\right|_{s=0}>\left.S W^{c}\right|_{s=0}
\end{array}\right. \\
& \text { and } s^{* c}>s^{* n c} \Rightarrow S C^{* c}>S C^{* c}
\end{aligned}
$$

Proof: Appendix A.

A research funding policy that optimally encourages both public and private $R \& D$ investments produces identical equilibrium results in the $c$ and $n c$ scenarios in terms of $\mathrm{R} \& \mathrm{D}$ output (public and private), consumer surplus and social welfare. As mentioned above, 
the socially optimal subsidy allocated to firms in each scenario compensates for spilloverdependent disincentives to $R \& D$ investment: in the absence of these subsidies, the $R \& D$ output and profits in the cooperative scenario are lower than in the non-cooperative case when the spillover level is less than 0.5. ${ }^{15}$ Higher subsidies allow cooperating firms to generate more R\&D and profit. The opposite holds when the spillover level is above 0.5.

As shown in Proposition 1, a mixed funding policy performs better than do policies that optimally subsidize just the private or just the public sector. In the absence of $R \& D$ subsidies to the private sector $(s=0)$, only public research is supported by state funding. In this case, the private sector still benefits freely from public knowledge externalities that stimulate its R\&D activity (see Equations 10 and 20) and R\&D cooperation produces more favorable outcomes than non-cooperation does in terms of all criteria when spillovers are high. The success of an R\&D policy in which only public research is funded $(s=0$ and $\alpha>0$ ) thus relies on firms choosing to cooperate. This is not the case for the mixed funding policy, whose effectiveness does not hinge on firms cooperating during the R\&D stage. When there is no public research sector $\left(x_{p u}=0\right)$, the corresponding knowledge externalities disappear and $\alpha=0$ in all equilibrium results (the denominator $\left.\Omega\right|_{\alpha=0}>\left.\Omega\right|_{\alpha>0}$ in Table 2). It follows readily that subsidizing only the private research sector is less effective than a mixed funding policy.

Funding both private and public research is more effective than only subsidizing public research (case where $s=0)$ or only subsidizing private $\mathrm{R} \& \mathrm{D}\left(x_{p u}=0\right)$. The improvement in social welfare under the optimal mixed funding policy stems first from the externalities generated by public research and second, from the subsidies stimulating production and $R \& D$ in the private sector when spillovers discourage R\&D. Ultimately, the increase in social welfare obtained from the optimal level of financial support for R\&D is not conditioned by the cooperative behavior of firms. However, if we consider the social cost of the funding policy $\left(S C^{*}\right)$, it is cheaper to subsidize cooperative rather than non-cooperative $\mathrm{R} \& \mathrm{D}$ investments when inter-firms spillovers are high $(>0.5)$.

These equilibrium results also show that bringing the two research sectors closer together (the effect of $\alpha$ ) always increases the R\&D output and consumer and producer surplus $\left(\frac{\partial \Omega}{\partial \alpha}<0\right.$ in Table 2$)$. This result suggests that it is indeed worthwhile for governments to promote interactions between the two sectors, compounding the increases in public and private $R \& D$ investment. Lemma 2 shows that the interest for firms of moving closer to public research bodies to benefit from knowledge externalities is all the greater when firms cooperate and the level of $R \& D$ appropriation is high (low spillovers), and when they compete in R\&D for high spillovers. More generally, if firms and public research bodies are far apart, the private sector necessarily receives a larger share of research funds to compensate for the loss of public knowledge externalities. However, our results clearly show that firms have an interest in moving closer to public laboratories, thereby stimulating the overall R\&D and increasing social welfare.

\footnotetext{
${ }^{15}$ See De Bondt (1997) and more recently Shibata (2014).
} 
Lemma $2 \forall n \geq 2$,

$$
\begin{aligned}
& 0<\frac{\partial \pi^{c}}{\partial \alpha}<\frac{\partial \pi^{n c}}{\partial \alpha} \quad \text { iff } \quad \beta>0.5 \\
& 0<\frac{\partial \pi^{n c}}{\partial \alpha}<\frac{\partial \pi^{c}}{\partial \alpha} \quad \text { iff } \quad \beta<0.5
\end{aligned}
$$

Proof: Appendix B.

We can now study and compare how the socially optimal government R\&D funding is distributed between the two sectors when firms cooperate in $R \& D$ and when they do not. The comparative statics for the private (public) sector's share of public R\&D funding show that:

Proposition 2 In both the nc and $c$ scenarios, the share of public RED funding allocated to the private research sector, $\theta$

(i) increases (decreases) when the efficiency of private (public) R\&D increases ( $\left.\frac{\gamma_{p r}}{\gamma_{p u}}\right)$,

(ii) decreases when public knowledge externalities ( $\alpha$ ) increase

(iii) increases with inter-firm spillovers $(\beta)$

(iv) increases with the number of firms when inter-firm spillovers are high enough and the industry is not highly concentrated.

Proof: Appendix C.

Part (i) of Proposition 2 shows that the proportion of public funding allocated to firms decreases when $\frac{\gamma_{p r}}{\gamma p u}$ increases, this factor being a measure of the relative efficiency of private and public research investments. If $\frac{\gamma_{p r}}{\gamma p u}>1$, private $\mathrm{R} \& \mathrm{D}$ is more costly than public research and under the optimal distribution of funding, the public sector receives the larger share. Public R\&D aids thus go mostly to the sector that produces research at a lower marginal cost per unit (the most efficient sector). In part (ii), it appears that increases in $\alpha$ also have a negative effect on the private sector's share. When the two sectors move closer together, the private sector absorbs more of the knowledge produced by the public sector, which makes subsidies to the private sector less efficient. Allocating a large share of funding to the public sector is then more efficient in terms of social welfare. Moreover, we show that the support for private R\&D investments increases with the degree of spillovers given the number of firms (part iii). The level of technological externalities differs between research domains. Some authors such as Bloom et al. (2013) differentiate firms performing $R \& D$ based on the industrial sector they belong to. The crucial difference is between basic and applied research. Applied research is typically easier 
to appropriate (low spillovers). On the other hand, basic research, which is typically easy to codify and disseminate, is harder for firms to appropriate (high spillovers). The latter situation leads to market failure and underinvestment in $\mathrm{R} \& \mathrm{D}$, which becomes more severe as the number of firms increases. This is why the private sector's optimal share of funding tends to increase with the number of firms (Part (iv) of the Proposition 2). Increasing subsidies for private $R \& D$ is one way of overcoming this $R \& D$ deficit. It is also recognized that $R \& D$ cooperation can correct these failures and that the benefit to social welfare from R\&D cooperation increases with the degree of spillovers. However, parts (iii) and (iv) highlight the fact that $R \& D$ cooperation alone is insufficient to solve the problem of underinvestment in $\mathrm{R} \& \mathrm{D}$ since the optimal share allocated to the private sector increases with spillovers and the number of firms. On the contrary, when the private sector shows low spillovers and high concentration $(n<5)$, it is better to increase the share of public funding allocated to public research regardless of whether firms cooperate or not in R\&D.

Even if subsidizing the private sector always performs better than offering no subsidies does (Proposition 1), the R\&D efficiency, the proximity between the research sectors, the type of $R \& D$ produced and the concentration of the industry must all be taken into account when deciding how best to promote research activities.

Proposition 3 For $s^{*}>0, \forall \quad n \geq 2 \quad \alpha \in(0,1]$,

$$
\theta^{n c}>\theta^{c} \quad \text { iff } \quad \beta>0.5, \quad \theta^{n c}=\theta^{c} \quad \text { iff } \quad \beta=0.5 \quad \text { and } \quad \theta^{n c}<\theta^{c} \quad \text { iff } \quad \beta<0.5
$$

Proof: Appendix D.

Proposition 3 reveals that when spillovers are high, firms receive a smaller share of public R\&D funding in the cooperative scenario than in a non-cooperative setting. The share of welfare-optimal funding allocated to support private $R \& D$ always increases with the degree of spillovers, but increases more in the non-cooperative scenario than in the cooperative one. This is because the subsidy for non-cooperative private investment in $R \& D$ always increases with the degree of spillovers; this is not the case when firms cooperate in $R \& D$. The optimal $R \& D$ subsidy in a cooperative setting depends only on the number of firms. The other policy tool for boosting public research investment $x_{p u}^{*}$ is not affected by the firms' cooperative strategy. As a result, the difference between the distributions of public funding in the two scenarios, $\theta^{n c}-\theta^{c}$, depends on the difference between the optimal levels of R\&D subsidies $s^{* n c}$ and $s^{* c}$ (see Lemma 1). This theoretical finding calls for lower R\&D subsidies with a larger share going to the public research sector when firms cooperate in R\&D and the sector spillover is sufficiently high. This means that if policymakers try to encourage collaborative research projects by systematically increasing subsidies, this can be welfare inefficient when spillovers are high. This result is illustrated in Figure 1. 


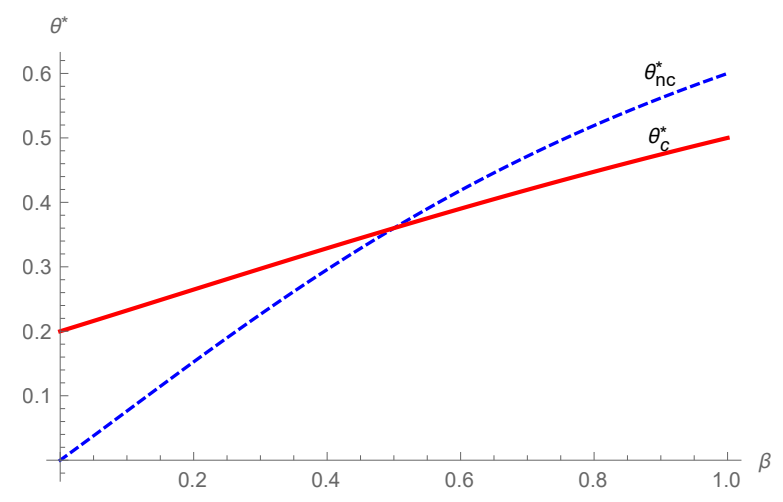

Figure 1: The private sector's share of public R\&D funding when $\alpha=1(n=2)$.

\section{Conclusion}

Over the past few years, OECD countries have adopted R\&D support policies that focus on promoting innovation by regrouping research bodies and encouraging cooperation. While there is empirical evidence that clusters improve economic performance, the impact, if any, of government policies encouraging the formation of clusters has seldom been studied (Lehmann and Menter, 2017). This article sheds some light on the effects of government R\&D subsidies in the context of clusters involving a public research laboratory. Our analysis clearly shows that increasing the proximity of public and private researchers increases both the firms' profits and social welfare. An important result is that this positive effect of proximity on welfare leads to an increase in the public sector's share of government $\mathrm{R} \& \mathrm{D}$ funding. We also show that subsidies that encourage cooperation in $R \& D$ between firms do not necessarily increase research output or social welfare compared with a non-cooperative $R \& D$ scenario. Whether the subsidized R\&D is conducted cooperatively or not does not affect the performance of the private research sector. However, the social cost of the research funding policy is lower when firms cooperate in R\&D for high inter-firms spillovers (the socially optimal proportion of the private sector's research spending subsidized by the state being lower).

This work is an entry point to the theoretical analysis of public support for private $\mathrm{R} \& \mathrm{D}$ but also of the role of public $\mathrm{R} \& \mathrm{D}$ in research cluster policies. It completes previous studies such as those by Cabon-Dhersin and Gibert (2018) and Cabon-Dhersin and Taugourdeau (2018). Note that our analysis assumes that firms benefit freely from the knowledge produced by the public sector and that the public sector does not benefit from externalities from the private sector. Furthermore, our analysis does not account for the possible effect of different forms of R\&D support. Finally, the allocation of subsidies is not contingent on the success of the R\&D project as in Atallah (2014). There are thus several avenues to explore for a better evaluation of $R \& D$ support policies in a cooperative context. 


\section{Appendix A Proof of Proposition 1}

1) Comparisons of $\left.x_{p r}^{n c}\right|_{s=0},\left.x_{p r}^{c}\right|_{s=0},\left.x_{p r}^{n c}\right|_{s^{n c}>0}$ and $\left.x_{p r}^{c}\right|_{s^{c}>0}$ :

Using Equations (10) and (20), we remark that:

$$
\left\{\begin{array}{l}
0<\left.X\right|_{s^{n c}>0}=\frac{\gamma_{p r}}{\gamma_{p u}}\left(2 \gamma_{p u}(n+1)^{2}-n(n+2) \alpha^{2}\right)(1-s)-2(n-\beta(n-1))(1+\beta(n-1))< \\
\frac{\gamma_{p r}}{\gamma_{p u}}\left(2 \gamma_{p u}(n+1)^{2}-n(n+2) \alpha^{2}\right)-2(n-\beta(n-1))(1+\beta(n-1))=\left.X\right|_{s=0} \\
0<\left.Y\right|_{s^{c}>0}=\frac{\gamma_{p r}}{\gamma_{p u}}\left(2 \gamma_{p u}(n+1)^{2}-n(n+2) \alpha^{2}\right)(1-s)-2(1+\beta(n-1))^{2}< \\
\frac{\gamma_{p r}}{\gamma_{p u}}\left(2 \gamma_{p u}(n+1)^{2}-n(n+2) \alpha^{2}\right)-2(1+\beta(n-1))^{2}=\left.Y\right|_{s=0}
\end{array}\right.
$$

As a consequence, from Equation 10 and Equation 20, we deduce:

$$
\left\{\begin{array}{l}
\left.\left.x_{p r}^{n c}\right|_{s_{n c}>0}=\frac{2(n-\beta(n-1))}{\left.X\right|_{s} n c>0}\right) \\
\left.x_{p r}^{c}\right|_{s_{c}>0}=\frac{2(1+\beta(n-1))}{\left.X\right|_{s^{n c}>0}} A>\frac{2(1+\beta(n-1))}{\left.Y\right|_{s=0}} A=\left.\left.x_{p r}^{c}\right|_{s=0} ^{n c}\right|_{s=0}
\end{array}\right.
$$

By comparing $\left.x_{p r}^{n c}\right|_{s=0}$ and $\left.x_{p r}^{c}\right|_{s=0}$, it can be easily checked that,

$$
\begin{gathered}
\operatorname{sign}\left(\left.x_{p r}^{n c}\right|_{s=0}-\left.x_{p r}^{c}\right|_{s=0}\right)= \\
\operatorname{sign}(2 Z((n-\beta(n-1))-(1+\beta(n-1))))=\operatorname{sign}((n-1)(1-2 \beta))
\end{gathered}
$$

with $Z=\frac{\gamma_{p r}}{\gamma_{p u}}\left(2 \gamma_{p u}(n+1)^{2}-n(n+2) \alpha^{2}\right)>0$

Hence, for all $n \geq 2$, we conclude that:

$\left.x_{p r}^{n c}\right|_{s=0}>\left.x_{p r}^{c}\right|_{s=0} \quad$ if $\quad \beta<0.5,\left.\quad x_{p r}^{n c}\right|_{s=0}=\left.x_{p r}^{c}\right|_{s=0} \quad$ if $\quad \beta=0.5,\left.\quad x_{p r}^{c}\right|_{s=0}<\left.x_{p r}^{n c}\right|_{s=0} \quad$ if $\quad \beta>0.5$

2) Comparisons of $\left.x_{p u}^{n c}\right|_{s=0},\left.\quad x_{p u}^{c}\right|_{s=0},\left.\quad x_{p u}^{n c}\right|_{s^{n c}>0}$ and $\left.\quad x_{p u}^{c}\right|_{s^{c}>0}$ :

From Equations (11) and (21) we have:

$$
\left\{\begin{array}{l}
\left.x_{p u}^{n c}\right|_{s_{n c}>0}>\left.x_{p u}^{n c}\right|_{s=0} \Leftrightarrow \frac{\frac{\gamma p r}{\gamma p u} n(n+2) \alpha(1-s)}{\left.X\right|_{s_{n c}>0}} A>\frac{\frac{\gamma p r}{\gamma p u} n(n+2) \alpha}{\left.X\right|_{s=0}} A \Leftrightarrow 2 s(1+\beta(n-1))(n-\beta(n-1))>0 \\
\left.x_{p u}^{c}\right|_{s_{c}>0}>\left.x_{p u}^{c}\right|_{s=0} \Leftrightarrow \frac{\frac{\gamma p r}{\gamma p u} n(n+2) \alpha(1-s)}{\left.Y\right|_{s_{n c}>0}} A>\frac{\frac{\gamma p r}{\gamma p u} n(n+2) \alpha}{\left.Y\right|_{s=0}} A \Leftrightarrow 2 s(1+\beta(n-1))^{2}>0
\end{array}\right.
$$

which are always verified.

and

$$
\begin{gathered}
\left.x_{p u}^{n c}\right|_{s=0}=\frac{\frac{\gamma_{p r}}{\gamma_{p u}} n(n+2) \alpha}{\left.X\right|_{s=0}} A>\frac{\frac{\gamma_{p r}}{\gamma_{p u}} n(n+2) \alpha}{\left.Y\right|_{s=0}} A=\left.x_{p u}^{c}\right|_{s=0} \\
\Leftrightarrow n-\beta(n-1)>1+\beta(n-1)
\end{gathered}
$$

Hence, we conclude that: 
$\left.x_{p u}^{n c}\right|_{s=0}>\left.x_{p u}^{c}\right|_{s=0} \quad$ if $\quad \beta<0.5,\left.\quad x_{p u}^{n c}\right|_{s=0}=\left.x_{p u}^{c}\right|_{s=0} \quad$ if $\quad \beta=0.5,\left.\quad x_{p u}^{c}\right|_{s=0}<\left.x_{p u}^{n c}\right|_{s=0} \quad$ if $\quad \beta>0.5$

3) Comparisons of $\left.Q^{n c}\right|_{s=0},\left.\quad Q^{c}\right|_{s=0},\left.\quad Q^{n c}\right|_{s^{n c}}$ and $\left.\quad Q^{c}\right|_{s^{c}}$ :

From Equations (12) and (22) we have:

$\left\{\begin{array}{l}\left.\left.Q^{n c}\right|_{s_{n c}>0}>\left.Q^{n c}\right|_{s=0} \Leftrightarrow \frac{2 n \gamma_{p r}(n+1)(1-s)}{\left.X\right|_{s n c}>0}\right) A>\frac{2 n \gamma_{p r}(n+1)}{\left.X\right|_{s=0}} A \Leftrightarrow 2 n s(1+\beta(n-1))(n-\beta(n-1))>0 \\ \left.Q^{c}\right|_{s_{c}>0}>\left.Q^{c}\right|_{s=0} \Leftrightarrow \frac{2 n \gamma_{p r}(n+1)(1-s)}{\left.Y\right|_{s_{n c}>0}} A>\frac{2 n \gamma_{p r}(n+1)}{\left.Y\right|_{s=0}} A \Leftrightarrow 2 n s(1+\beta(n-1))^{2}>0\end{array}\right.$

which are always verified.

and

$$
\left.Q^{n c}\right|_{s=0}=\frac{2 n \gamma_{p r}(n+1)}{\left.X\right|_{s=0}} A>\frac{2 n \gamma_{p r}(n+1)}{\left.Y\right|_{s=0}} A=\left.Q^{c}\right|_{s=0}
$$

This inequality is satisfied if:

$$
\left.X\right|_{s=0}<\left.Y\right|_{s=0} \Leftrightarrow n-\beta(n-1)>1+\beta(n-1)
$$

Hence, for all $n \geq 2$, we conclude that:

- $\left.Q^{n c}\right|_{s=0}>\left.Q^{c}\right|_{s=0}$ if $\beta<0.5$

- $\left.Q^{n c}\right|_{s=0}=\left.Q^{c}\right|_{s=0} \quad$ if $\beta=0.5$

- $\left.Q^{n c}\right|_{s=0}<\left.Q^{c}\right|_{s=0}$ if $\beta>0.5$

4) Comparisons between $\left.\pi^{n c}\right|_{s_{n c}>0}$ and $\left.\pi^{c}\right|_{s_{c}>0}$ :

From Equations (13) and (23):

$$
\begin{gathered}
\left.\pi^{n c}\right|_{s_{n c}>0}=\frac{4 \gamma_{p r}(1-s)\left((n+1)^{2}(1-s)-(n-\beta(n-1))^{2}\right)}{\left(\left.X\right|_{s_{n c}>0}\right)^{2}} A^{2}> \\
\frac{4 \gamma_{p r}(1-s)\left((n+1)^{2}(1-s)-(1+\beta(n-1))^{2}\right)}{\left(\left.Y\right|_{s_{c}>0}\right)^{2}} A^{2}=\left.\pi^{c}\right|_{s_{c}>0}
\end{gathered}
$$

This inequality is satisfied if:

$$
\left.X\right|_{s_{n c}>0}<\left.Y\right|_{s_{c}>0} \Leftrightarrow n-\beta(n-1)<1+\beta(n-1) \Leftrightarrow \beta>0.5
$$

and

$$
\begin{gathered}
4 \gamma_{p r}(1-s)\left((n+1)^{2}(1-s)-(n-\beta(n-1))^{2}\right)>4 \gamma_{p r}(1-s)\left((n+1)^{2}(1-s)-(1+\beta(n-1))^{2}\right) \\
\Leftrightarrow n-\beta(n-1)<1+\beta(n-1) \Leftrightarrow \beta>0.5
\end{gathered}
$$

Hence, we conclude that: 
- $\left.\pi^{n c}\right|_{s_{n c}>0}<\left.\pi^{c}\right|_{s_{c}>0}$ if $\beta<0.5$

- $\left.\pi^{n c}\right|_{s_{n c}>0}=\left.\pi^{c}\right|_{s_{c}>0}$ if $\beta=0.5$

- $\left.\pi^{c}\right|_{s_{n c}>0}>\left.\pi^{n c}\right|_{s_{c}>0}$ if $\beta>0.5$

5) Comparisons between $\left.S W^{n c}\right|_{s=0}$ and $\left.S W^{c}\right|_{s=0}$ :

Similarly, from Equations (14) and (24) with $s=0$, we have

$$
\operatorname{sign}\left(\left.S W^{n c}\right|_{s=0}-\left.S W^{c}\right|_{s=0}\right)=\operatorname{sign}(1-2 \beta)
$$

Hence, we conclude that:

- $\left.S W^{n c}\right|_{s=0}>\left.S W^{c}\right|_{s=0}$ if $\beta<0.5$

- $\left.S W^{n c}\right|_{s=0}=\left.S W^{c}\right|_{s=0}$ if $\beta=0.5$

- $\left.S W^{n c}\right|_{s=0}<\left.S W^{c}\right|_{s=0}$ if $\beta>0.5$

6) Comparisons between $\left.S W^{n c}\right|_{s^{n c}}$ and $\left.S W^{n c}\right|_{s=0}$ :

From Equation 14 and Table 2, we calculate the difference

$$
\begin{gathered}
\left.S W^{n c}\right|_{s^{n c}>0}-\left.S W^{n c}\right|_{s=0}= \\
\gamma_{p r} n\left(\frac{(n+2)}{Z-(2+n)(1+\beta(n-1))^{2}}-\frac{\left((n+2) Z-4(n-\beta(n-1))^{2}\right)}{(Z-2(n-\beta(n-1))(1+\beta(n-1)))^{2}}\right) A^{2}
\end{gathered}
$$

it can be easily checked that

$$
\begin{gathered}
\operatorname{sign}\left(\left.S W^{n c}\right|_{s^{n c}}-\left.S W^{n c}\right|_{s=0}\right)= \\
\operatorname{sign}\left((n+2)(Z-2 \tau \psi)^{2}-\left((n+2) Z-4 \tau^{2}\right)\left(Z-(n+2) \psi^{2}\right)\right) \\
=\operatorname{sign}\left(Z(2 \tau-(n+2) \psi)^{2}\right)>0
\end{gathered}
$$

with $\tau=n-\beta(n-1)$ and $\psi=1+\beta(n-1)$

we can deduce:

$$
\left.S W^{n c}\right|_{s^{n c}}>\left.S W^{n c}\right|_{s=0}
$$

7) Comparisons between $\left.S W^{c}\right|_{s^{c}}$ and $\left.S W^{c}\right|_{s=0}$ :

From Equation 24 and Table 1, we calculate the difference

$$
\left.S W^{c}\right|_{s^{c}>0}-\left.S W^{c}\right|_{s=0}=
$$




$$
\gamma_{p r} n\left(\frac{(n+2)}{Z-(2+n) \psi^{2}}-\frac{\left((n+2) Z-4 \psi^{2}\right)}{\left(Z-2 \psi^{2}\right)^{2}}\right) A^{2}
$$

It's easily checked that

$$
\operatorname{sign}\left(\left.S W^{c}\right|_{s^{c}}-\left.S W^{c}\right|_{s=0}\right)=\operatorname{sign}\left(n^{2} Z \psi^{2}\right)>0
$$

As a consequence, we conclude that $\left.S W^{c}\right|_{s^{c}}>\left.S W^{c}\right|_{s=0}$

\section{Appendix B Proof of Lemma 2}

From Table 2, differentiation of equilibrium profits $\pi^{n c}$ and $\pi^{c}$ with respect to $\alpha$ yields:

$$
\frac{\partial \pi^{n c}}{\partial \alpha}=-\frac{2 \Omega_{\alpha}^{\prime} \Omega}{\Omega^{4}}\left(2 \gamma_{p r}\left(2(n+1)^{2} \gamma_{p u}-(n+2) \tau \psi\right)\right) A^{2}
$$

And:

$$
\frac{\partial \pi^{c}}{\partial \alpha}=-\frac{2 \Omega_{\alpha}^{\prime} \Omega}{\Omega^{4}}\left(2 \gamma_{p r}\left(2(n+1)^{2} \gamma_{p u}-(n+2) \psi^{2}\right)\right) A^{2}
$$

with $\Omega_{\alpha}^{\prime}<0$ and $\Omega>0$.

It can be easily checked that,

$\operatorname{sign}\left(\frac{\partial \pi^{n c}}{\partial \alpha}-\frac{\partial \pi^{c}}{\partial \alpha}\right)=\operatorname{sign}\left((n+2)\left(-\tau \psi+\psi^{2}\right)\right)=\operatorname{sign}(-\tau+\psi)=\operatorname{sign}(-(n-1)+2 \beta(n-1))$

Hence, we conclude that:

- $\forall \beta>0.5, \frac{\partial \pi^{n c}}{\partial \alpha}>\frac{\partial \pi^{c}}{\partial \alpha}>0$

- $\forall \beta=0.5, \frac{\partial \pi^{n c}}{\partial \alpha}=\frac{\partial \pi^{c}}{\partial \alpha}>0$

- $\forall \beta<0.5, \frac{\partial \pi^{c}}{\partial \alpha}>\frac{\partial \pi^{n c}}{\partial \alpha}>0$

\section{Appendix C Proof of Proposition 2}

For i), ii) and iii), the proofs are obvious from Equations (16) and (26). For iv), differentiation of $\theta^{n c}$ and $\theta^{c}$ with respect to $n$ yields:

$$
\begin{gathered}
\frac{\partial\left(1-\theta^{n c}\right)}{\partial n}=\frac{\alpha^{2} \frac{\gamma_{p r}}{\gamma_{p u}}}{F^{2}}((\beta(n-1)(4+n)-(n-2))(2(n+1)(1+\beta(n-1))-\beta n(n+2))- \\
n(n+2)(1+\beta(n-1))(\beta(3+2 n)-1))
\end{gathered}
$$

The denominator in the above expression is positive; hence the sign of the derivative is determined by the sign of numerator. Rearranging and simplifying we obtain 


$$
\operatorname{sign}\left(\frac{\partial \theta^{n c}}{\partial n}\right)=
$$

$\operatorname{sign}\left(\beta^{2}(n-1)(2(2 n+1)(4+n)+n(n+2)(n-1))-\beta 6\left((n-1)^{2}-3\right)+(n-2)^{2}-8\right)$

$\forall n>4, \operatorname{sign}\left(\frac{\partial \theta^{n c}}{\partial n}\right)$ is always positive $\forall \beta \in(0,1]$.

When $n<5, \frac{\partial \theta^{n c}}{\partial n}>0$ iff $\beta>\tilde{\beta}$ with

$\tilde{\beta}=\frac{6\left((n-1)^{2}-3\right)+\sqrt{36\left((n-1)^{2}-3\right)^{2}-4 \beta^{2}(n-1)(2(2 n+1)(4+n)+n(n+2)(n-1))\left((n-2)^{2}-8\right)}}{2(n-1)(2(2 n+1)(4+n)+n(n+2)(n-1))}$

Differentiation of $\theta^{c}$ with respect to $n$ yields

$$
\operatorname{sign}\left(\frac{\partial \theta^{c}}{\partial n}\right)=\operatorname{sign}(\beta(n+5)-1)
$$

Figures 2 illustrate the effect of $n$ on the distribution of public funding between private and public research sectors.
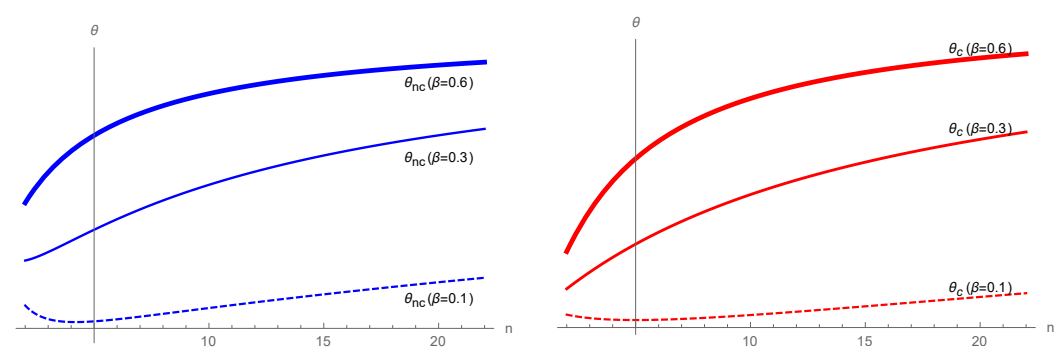

Figure 2: Effect of $n$ on the distribution $\theta$.

\section{Appendix D Proof of Proposition 3}

From Equation (4) and Table 2

$$
\theta^{n c, c}=\frac{s^{* n c, c} \gamma_{p r} n x_{p r}^{2}}{s^{* n c, c} \gamma_{p r} n x_{p r}^{2}+\gamma_{p u} x_{p u}^{2}}=\frac{s^{* n c, c}(1+\beta(n-1))^{2}}{s^{* n c, c}(1+\beta(n-1))^{2}+n \alpha^{2} \frac{\gamma_{p r}}{\gamma_{p u}}}
$$

and

$$
\left(1-\theta^{n c, c}\right)=\frac{n \alpha^{2} \frac{\gamma_{p r}}{\gamma_{p u}}}{s^{* n c, c}(1+\beta(n-1))^{2}+n \alpha^{2} \frac{\gamma_{p r}}{\gamma_{p u}}}
$$

When $s^{* n c}>(<) s^{* c},\left(1-\theta^{n c}\right)<(>)\left(1-\theta^{c}\right)$ and $\theta^{n c}>(<) \theta^{c}$.

From Lemma $1, s^{* n c}>(<) s^{* c}$ iff $\beta>(<) 0.5$. 


\section{References}

Amir, R. (2000). Modelling imperfectly appropriable R\&D via spillovers. International Journal of Industrial Organization, 18(7):1013-1032.

Amir, R., Evstigneev, I., and Wooders, J. (2003). Noncooperative versus cooperative R\&D with endogenous spillover rates. Games and Economic Behavior, 42(2):183-207.

Amir, R. and Wooders, J. (2000). One-way spillovers, endogenous innovator/imitator roles, and research joint ventures. Games and Economic Behavior, 31(1):1-25.

Anselin, L., Varga, A., and Acs, Z. (1997). Local geographic spillovers between university research and high technology innovations. Journal of Urban Economics, 42(3):422-448.

Atallah, G. (2014). Conditional R\&D subsidies. Economics of Innovation and New Technology, 23(2):179-214.

Audretsch, D. B., Bozeman, B., Combs, K. L., Feldman, M., Link, A. N., Siegel, D. S., Stephan, P., Tassey, G., and Wessner, C. (2002). The economics of science and technology. The Journal of Technology Transfer, 27(2):155-203.

Autant-Bernard, C. (2001). Science and knowledge flows: evidence from the French case. Research policy, 30(7):1069-1078.

Autant-Bernard, C. and LeSage, J. P. (2011). Quantifying knowledge spillovers using spatial econometric models. Journal of Regional Science, 51(3):471-496.

Becker, B. (2015). Public R\&D policies and private R\&D investment: A survey of the empirical evidence. Journal of Economic Surveys, 29(5):917-942.

Bloom, N., Schankerman, M., and Van Reenen, J. (2013). Identifying technology spillovers and product market rivalry. Econometrica, 81(4):1347-1393.

Cabon-Dhersin, M.-L. (2008). R\&D cooperation and collusion: the case of joint labs. The Manchester School, 76(4):424-435.

Cabon-Dhersin, M.-L. and Gibert, R. (2018). Cooperation or non-cooperation in R\&D: how should research be funded? Economics of Innovation and New Technology, Forthcoming.

Cabon-Dhersin, M.-L. and Taugourdeau, E. (2018). Location and research activities organization: Could public-private cooperation be harmful? Papers in Regional Science, 97(4):883-907.

Cabral, L. M. (2000). R\&d cooperation and product market competition. International Journal of Industrial Organization, 18(7):1033-1047. 
Cohen, S., Florida, R., and Coe, W. (1994). University-industry partnerships in the US. Pittsburgh: Carnegie-Mellon University.

Cohen, W. M., Nelson, R. R., and Walsh, J. P. (2002). Links and impacts: the influence of public research on industrial R\&D. Management Science, 48(1):1-23.

Cooke, P. (2001). From technopoles to regional innovation systems: the evolution of localised technology development policy. Canadian Journal of Regional Science, 24(1):2140 .

d'Aspremont, C. and Jacquemin, A. (1988). Cooperative and noncooperative R\&D in duopoly with spillovers. The American Economic Review, 78(5):1133-1137.

De Bondt, R. (1997). Spillovers and innovative activities. International Journal of Industrial Organization, 15(1):1-28.

De Fraja, G. and Silipo, D. B. (2002). Product market competition, r\&d, and welfare. Research in Economics, 56(4):381-397.

Dimos, C. and Pugh, G. (2016). The effectiveness of r\&d subsidies: A meta-regression analysis of the evaluation literature. Research Policy, 45(4):797-815.

Furman, J. L., Kyle, M. K., Cockburn, I. M., and Henderson, R. (2006). Public \& private spillovers, location and the productivity of pharmaceutical research. Technical report, National Bureau of Economic Research.

Gil-Moltó, M. J., Poyago-Theotoky, J., Neto, J. R., and Zikos, V. (2018). Mixed oligopoly, privatization and $\mathrm{r} \& d$ subsidization.

Gil-Molto, M. J., Poyago-Theotoky, J., and Zikos, V. (2011). R\&D subsidies, spillovers and privatization in mixed markets. Southern Economic Journal, 78(1):233-255.

Hinloopen, J. (2000). More on subsidizing cooperative and noncooperative R\&D in duopoly with spillovers. Journal of Economics, 72(3):295-308.

Inci, E. (2009). R\&D tax incentives: a reappraisal. International Tax and Public Finance, $16(6): 797-821$.

Jaffe, A. B. (1989). Real effects of academic research. The American Economic Review, $79(5): 957-970$.

Kamien, M. I., Muller, E., and Zang, I. (1992). Research joint ventures and R\&D cartels. The American Economic Review, 82(5):1293-1306.

Katz, M. L. (1986). An analysis of cooperative research and development. The RAND Journal of Economics, pages 527-543. 
Kesavayuth, D. and Zikos, V. (2013). R\&D versus output subsidies in mixed markets. Economics Letters, 118(2):293-296.

Lambertini, L., Poddar, S., and Sasaki, D. (2003). Rjvs in product innovation and cartel stability. Review of Economic Design, 7(4):465-477.

Leahy, D. and Neary, J. P. (1997). Public policy towards R\&D in oligopolistic industries. The American Economic Review, pages 642-662.

Lehmann, E. E. and Menter, M. (2017). Public cluster policy and performance. The Journal of Technology Transfer, pages 1-35.

Marinucci, M. (2012). A primer on R\&D cooperation among firms. https://ssrn.com/abstract=2159243.

Motta, M. (1992). Cooperative r\&d and vertical product differentiation. International Journal of Industrial Organization, 10(4):643-661.

Poyago-Theotoky, J. (1995). Equilibrium and optimal size of a research joint venture in an oligopoly with spillovers. The Journal of Industrial Economics, pages 209-226.

Salant, S. W. and Shaffer, G. (1998). Optimal asymmetric strategies in research joint ventures. International Journal of Industrial Organization, 16(2):195-208.

Shibata, T. (2014). Market structure and r\&d investment spillovers. Economic Modelling, 43:321-329.

Veugelers, R. and Cassiman, B. (2005). R\&D cooperation between firms and universities. Some empirical evidence from Belgian manufacturing. International Journal of Industrial Organization, 23:355-379. 